Check for updates

Cite this: Chem. Sci., 2019, 10, 2081

๑ All publication charges for this article have been paid for by the Royal Society of Chemistry

Received 15th November 2018 Accepted 27th November 2018

DOI: $10.1039 / \mathrm{c} 8 \mathrm{sc} 05104 f$

rsc.li/chemical-science

\section{Chemical operations on a living single cell by open microfluidics for wound repair studies and organelle transport analysis $\uparrow$}

\author{
Sifeng Mao, (D) a Qiang Zhang, (D) ${ }^{a}$ Wu Liu, ${ }^{a}$ Qiushi Huang, (D) a Mashooq Khan, (D) a \\ Wanling Zhang, ${ }^{a}$ Caihou Lin, ${ }^{b}$ Katsumi Uchiyama (iD c and Jin-Ming Lin (D) *a
}

\begin{abstract}
Single cells are increasingly recognized to be capable of wound repair that is important for our mechanistic understanding of cell biology. The lack of flexible, facile, and friendly subcellular treatment methods has hindered single-cell wound repair studies and organelle transport analyses. Here we report a laminar flow based approach, we call it fluid cell knife (Fluid $\mathrm{CK}$ ), that is capable of precisely cutting off or treating a portion of a single cell from its remaining portion in its original adherent state. Local operations on portions of a living single cell in its adherent culture state were applied to various types of cells. Temporal wound repair was successfully observed. Moreover, we successfully stained portions of a living single cell to measure the organelle transport speed (mitochondria as a model) inside a cell. This technique opens up new avenues for cellular wound repair and subcellular behavior analyses.
\end{abstract}

\section{Introduction}

Commonly, complex organisms are built from one, then two, then four seemingly identical cells of an embryo. ${ }^{1-4}$ Single cell analysis for cell type and activity has been confirmed a greater challenge than conventional studies on populations of cells. ${ }^{5-9}$ The importance of single-cell biology has sharply increased in recent years. Advances in new tools allow biologists to explore the characteristics of an individual cell. Single-cell biology promotes scientists to dissect the mysteries of life, one cell at a time. ${ }^{10,11}$ Wound repair is an essential feature for differentiating living beings from non-living matter, and these repair activities can also be observed at the single-cell level. ${ }^{12}$ More and more scientists have tried to understand wound repair at the single-cell level. ${ }^{13}$

Massive efforts have been made into new approaches for single-cell analysis, ${ }^{14,15}$ including optical tweezers, ${ }^{16,17}$ microfluidic chips, ${ }^{18-20}$ dual capillary probes, ${ }^{21}$ and microfluidic probes. ${ }^{22}$ These technologies have greatly promoted single-cell research, such as single-cell metabolism, ${ }^{23-25}$ whole-genome sequencing analysis ${ }^{26,27}$ from single cells and cell-cycle

\footnotetext{
${ }^{a}$ Department of Chemistry, Beijing Key Laboratory of Microanalytical Methods and Instrumentation, MOE Key Laboratory of Bioorganic Phosphorus Chemistry \& Chemical Biology, Tsinghua University, Beijing 100084, China. E-mail: jmlin@mail. tsinghua.edu.cn

${ }^{b}$ Department of Neurosurgery, Fujian Medical University Union Hospital, Fuzhou, Fujian 350001, China

${ }^{c}$ Department of Applied Chemistry, Graduate School of Urban Environmental Sciences, Tokyo Metropolitan University, Minamiohsawa, Hachioji, Tokyo 192-0397, Japan

$\dagger$ Electronic supplementary information (ESI) available. See DOI: $10.1039 / \mathrm{c} 8 \mathrm{sc} 05104 \mathrm{f}$
}

dynamics of single cells. ${ }^{28}$ However, the cell itself is not homogeneous, and more efforts should be made in developing new tools for subcellular studies to understand the regional differences of a single cell. Moreover, operations on a portion of a cell are vital for understanding cell wound repair, signal transduction and molecule transfer in cells.

Microsampling methods, ${ }^{29-31}$ and fluidic force microscopy $^{32-34}$ have performed well for the sampling of cellular contents. The use of a nanopipette has been demonstrated to be a convenient approach for precise drug infusion into a cell. The requirements of these technologies to have cell insertion operations means that they are harmful to live cells. Physical operations of tissues and cells by a knife or a needle have suffered from low spatial resolution. Microdissection ${ }^{35}$ has become the best choice for tissue and cell separation with high resolution. Yet, it is still difficult to operate on a portion of a cell, because the resolution is not high enough. Laminar flow in a microfluidic chip $^{36,37}$ has been reported as a powerful tool for subcellular positioning and microenvironment control. However, cells should be cultured in the microchannel for treatment, because laminar flow is generated in a closed microchannel. ${ }^{36}$ Recently, microfluidic probes ${ }^{38,39}$ and chemical pens $^{\mathbf{4 0 - 4 2}}$ have been reported as promising approaches for fluid and laminar flow control in open spaces. Yet, precise operations and treatments of portions of a cell in situ are still of vital importance for subcellular studies.

In this work, we report a fluid cell knife, a highly flexible microfluidic methodology, which provides users with the abilities to cut off a portion of a living single cell at a precise position and treat portions of cells. The Fluid CK enables local excision of a desired single-cell and microenvironment control 
of a partial cell. In conventional methods $\mathrm{s}^{\mathbf{4 3 - 4 5}}$ for generating confined flow in an open space, the interface of the solution of interest with the adjacent one has remarkable positional fluctuations caused by the elasticity of the pathway and vibrations of pumps. It is difficult to maintain a stable interface at a precise position. The present device was designed with a symmetrical geometry, so the two solutions could contact each other to counteract the fluctuation. Benefiting from the symmetrical geometry, the interface of the two adjacent solutions was extremely stable.

\section{Results and discussion}

The Fluid CK was designed with symmetrical geometry containing four identical apertures (Fig. 1a). The manufacture of the device is detailed in Fig. S1. $\dagger$ The tip of the Fluid CK was placed perpendicular to the cell sample surface, and both were immersed in the surrounding medium (Fig. 1a and S2 $\dagger$ ). A "gap" existed between the tip of the Fluid CK and the sample surface. Solution A (red) and solution B (green) were injected into the device through two opposite apertures that were connected to two individual gas-tight syringes driven by one pump. The other two apertures were for solution aspiration by the connection to two individual gas-tight syringes driven by another pump. A planar interface across the centers of the two aspiration apertures was generated. The cell was manipulated to make the interface at a desirable subcellular position, resulting in one portion of the cell being immersed in solution $\mathrm{A}$ and the other portion in solution B (Fig. 1b). In one case, solution A was cell culture medium and solution B was cell lysis buffer. The portion in solution B would be cut off, while the
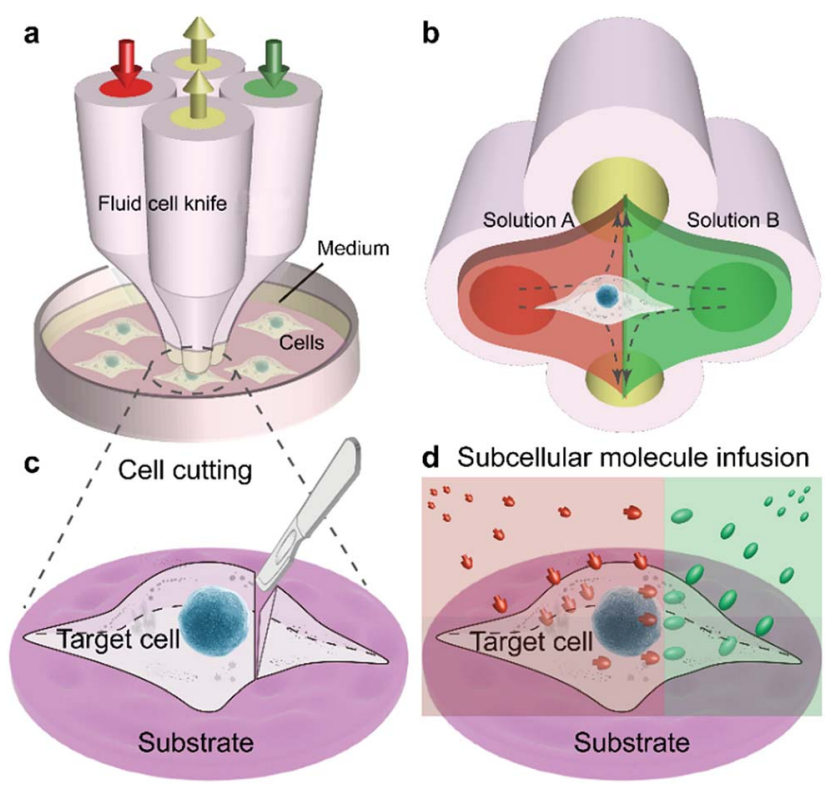

Fig. 1 Fluid cell knife (Fluid CK) for precise chemical operations on single cells. (a) Design and operation of the Fluid CK. (b) The principle of fluid control for partial treatment. (c) Illustration of precise cutting operations on a single cell. (d) Subcellular molecular infusion of a single cell using the Fluid CK. other portion was well protected by the cell culture medium and left on the substrate (Fig. 1c). Therefore, the Fluid CK functioned as a lancet to slice a single cell. In another case, solution A and solution B contained different species, so different portions of the cell were infused with different types of molecules (Fig. 1d). Subcellular molecular infusions were achieved for partial cell staining and analyses of organelle transport. In the later experiments, the injected solutions were stopped first while aspirations were maintained. Thus, all solutions injected out would be totally aspirated back into the device. Then, the device was removed away and operations were finished.

Finite element analysis (FEA) for the fluid underneath the Fluid CK was carried out using the commercially available software COMSOL Multiphysics 5.3 (Comsol). Navier-Stokeequations and convection-diffusion equation were coupled in the FEA. The geometry of the model was identical to the device used in the experiments (Fig. 2a). Unless stated otherwise, the injection flow rate $\left(R_{\mathrm{i}}\right)=1 \mu \mathrm{L} \mathrm{min}^{-1}$, the aspiration flow rate

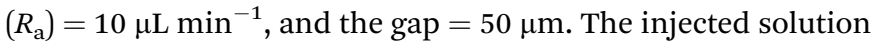
containing fluorescein $\left(1 \mu \mathrm{g} \mathrm{mL} \mathrm{m}^{-1}\right.$, equal to $\left.3 \mu \mathrm{M}\right)$ as a diffusive species indicated the microjet region. The diffusion coefficient of fluorescein is $500 \mu \mathrm{m}^{2} \mathrm{~s}^{-1}$. $^{37}$ The bottom views of the streamlines and the velocity field at the substrate are shown in Fig. $2 \mathrm{~b}$ and c, respectively. Both appeared to have symmetrical distributions.

The velocity profiles along line $\mathrm{XX}^{\prime}$ and $\mathrm{YY}^{\prime}$ were calculated (Fig. S3†). The concentration distribution of the species (Fig. 2d)
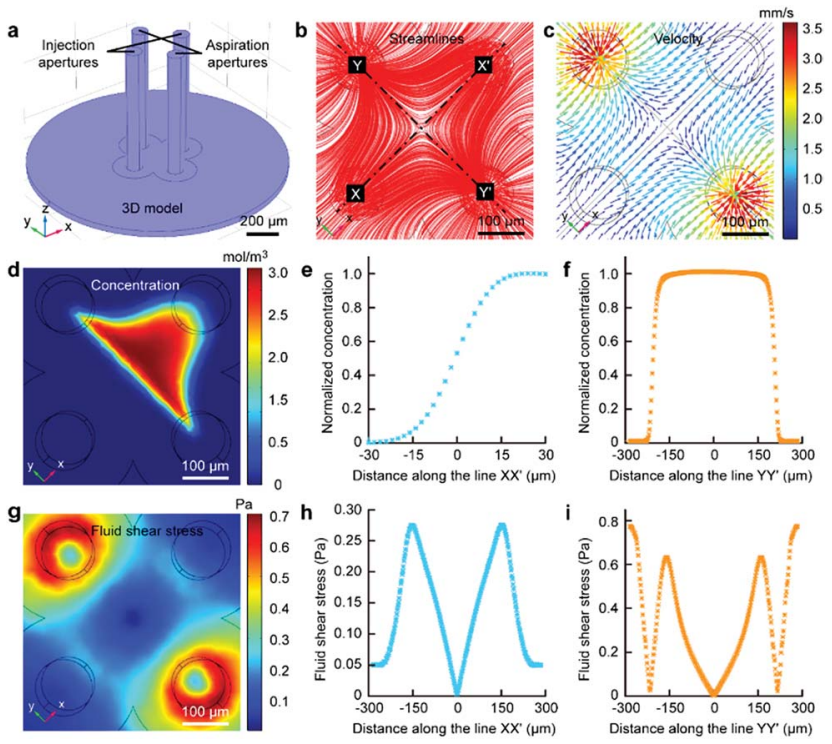

Fig. 2 Microjet underneath the Fluid CK in FEA. (a) Geometry of the Fluid $\mathrm{CK}$ used in the simulation. (b) Flow streamline fields. (c) Velocity distribution at the substrate. (d) Concentration distributions of the diffusive species at the substrate. (e) Concentration profile of the diffusive species at the substrate along the line $X X^{\prime}$ connecting the two injection apertures. (f) Concentration profile of the diffusive species at the substrate along the line $Y Y^{\prime}$ connecting the two aspiration apertures. (g) Calculated fluid shear stress at the substrate surface. (h) Fluid shear stress profile at the substrate along the line $X X^{\prime}$ connecting the two injection apertures. (i) Fluid shear stress profile at the substrate along the line $Y Y^{\prime}$ connecting the two aspiration apertures. 
had a planar interface along line $\mathrm{YY}^{\prime}$. A concentration gradient existed along line $\mathrm{XX}^{\prime}$ (Fig. 2e). Significantly, a uniform concentration was observed along line $\mathrm{YY}^{\prime}$ near the center (Fig. 2f), which indicated proper function of the laminar flow within this spatial range. As cells are sensitive to fluid shear stress (FSS), ${ }^{\mathbf{4 6 , 4 7}}$ FSS distributions near the substrate were calculated (Fig. 2g). The FSS at the point near the center (with a distance smaller than $50 \mu \mathrm{m}$ ) was sufficiently lower than 0.1 $\mathrm{Pa}$ (Fig. 2h and i), which would not harm the cell. ${ }^{46}$ Negative pressure relative to atmospheric pressure existed between the two apertures at the substrate (Fig. S4 $\dagger$ ). The maxima of FSS (Fig. S5 $\dagger$ ), velocity (Fig. S6 $\dagger$ ) and pressure (Fig. S7†) were linear with the flow ratio as well as the injection flow rate. We could adjust those elements conveniently to meet further requirements in applications.

The structure of the Fluid CK (ESI Fig. S8a and $\mathrm{b} \dagger$ ) and the flatness of the tip surface (Fig. S8c $\dagger$ ) were characterized using a scanning electron microscope (SEM). The zone of injected flow was confirmed using a fluorescein solution (Fig. 3a), and it was consistent with the results of the FEA. The boundaries were defined as $10 \%$ of the local maximum of fluorescence intensity. A planar interface with high stability was observed. Because of the flow fluctuations caused by the stepper motor in the pump and the elasticity of the Fluid CK and the connecting tube, the fluctuation amplitude $\left(A_{y}\right)$ of the boundaries at the $y$-axis (point $\mathrm{Q}$ in Fig. 3a) was extremely large (Fig. 3b). In contrast, the flow fluctuation amplitude $\left(A_{x}\right)$ at the $x$-axis (point $\mathrm{P}$ ) was extremely small because the symmetry of the two injected solutions offset the undesirable fluctuations (Fig. 3b), which suggested a stable interface. $A_{x}$ showed no significant change when the ratio was higher than 10 (Fig. $3 \mathrm{~b}$ and $\mathrm{S} 9 \dagger$ ). Thus, the optimal ratio was selected as 10 . Keeping a constant $R_{\mathrm{a}} / R_{\mathrm{i}}, A_{x}$ and $A_{y}$ decreased with increasing $R_{\mathrm{i}} . A_{x}$ was as small as $1 \mu \mathrm{m}$ (Fig. $3 \mathrm{c}$ and $\mathrm{S} 10 \dagger$ ) when $R_{\mathrm{i}}$ was $1 \mu \mathrm{L} \min ^{-1}$. The resolution was high enough for subcellular analysis. Those conditions were optimal in the latter experiments. The results suggested that the Fluid CK was capable of generating an extremely stable interface between two adjacent miscible solutions, and the reason for this is due to the symmetrical design.

A portion of a single cell was immersed in a certain solution environment near the interface. Therefore, the molecules in this solution environment would selectively treat the desired portion of the cell. In the subcellular cutting operation, RIPA non-denaturing tissue lysis buffer was injected into the upper right aperture, and cell culture medium was injected into the lower left aperture. The lysis buffer functioned for cutting portions of the cell, while the cell culture medium functioned for protecting other portions of the cell. The injection and aspiration flow rates were 1 and $10 \mu \mathrm{L} \mathrm{min}{ }^{-1}$, respectively. The gap was $50 \mu \mathrm{m}$. Laminar flows were generated underneath the Fluid CK and a planar interface existed (the white dotted line in Fig. 3e-i). The target cell (an adherent cultured U87 cell) was a

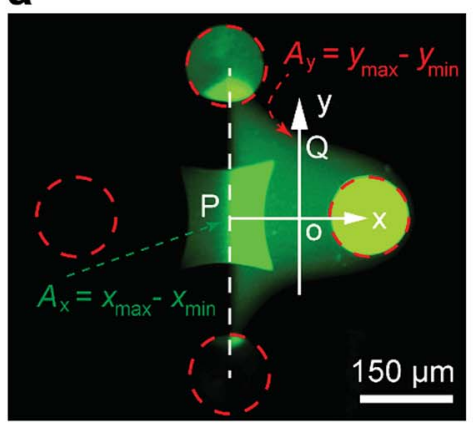

C

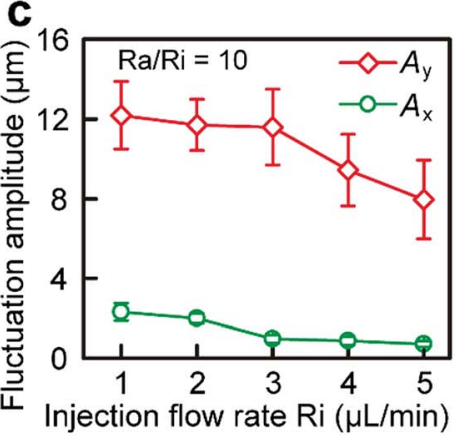

b

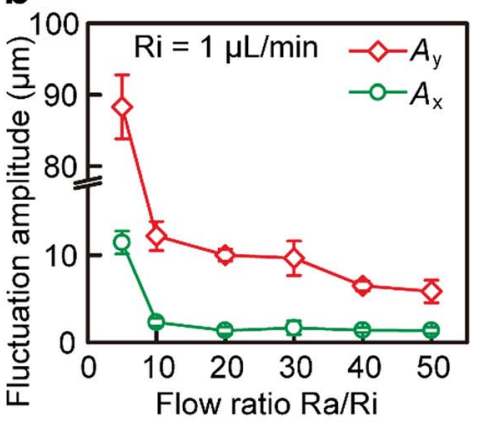

d

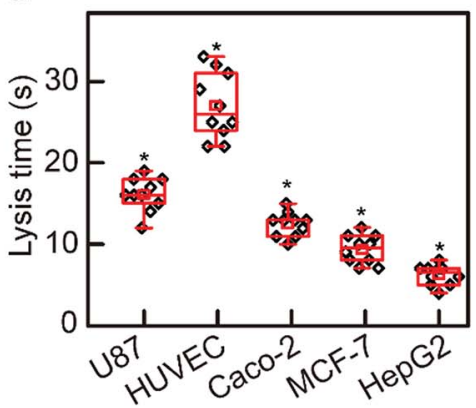

e

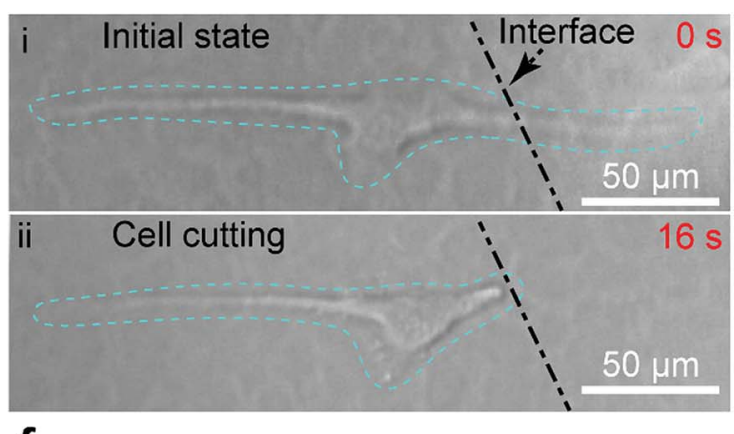

f

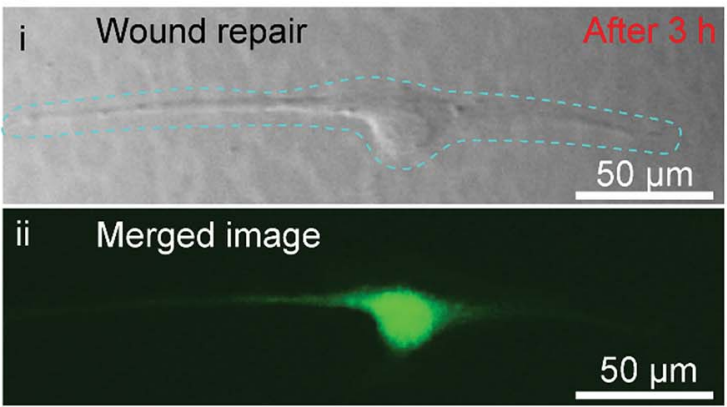

Fig. 3 Stability of the interface between two miscible solutions underneath the Fluid CK and cell cutting for wound repair studies. (a) Fluorescent image of the microjet underneath the Fluid CK used in the experiments. (b) Fluctuation amplitude at the point $A$ on $x$-axis and point $B$ on $y$-axis under different flow ratio $R_{\mathrm{a}} / R_{\mathrm{i}}$. The injection flow rate was constant $\left(1 \mu \mathrm{L} \mathrm{min}{ }^{-1}\right)$. (c) Fluctuation amplitude at point $\mathrm{A}$ on the $x$-axis and point $\mathrm{B}$ on the $y$-axis under different injection flow rates, $R_{\mathrm{i}}$. The flow ratio $R_{\mathrm{a}} / R_{\mathrm{i}}$ was constant (equal to 10 ). (d) The lysis time for different types of cells. $\mathrm{A}$ two-tailed Student's $t$-test was performed. $* P<0.05$. (e) Single-cell cutting processes, including (i) the initial state, and (ii) the state of the target single-cell after precise cutting. (f) Wound repair after $3 \mathrm{~h}$, including (i) a bright field image of the cell after wound repair, and (ii) a corresponding merged image stained using a Live/Dead kit. 
positioned in the cell culture medium environment first (Fig. S11a $\dagger$ ), and then moved towards and crossed the interface gradually. The portion of cell immersed in the lysis buffer environment was cut off rapidly (less than $20 \mathrm{~s}$ ) (Fig. S11b, ESI Movie $\mathrm{S} 1 \dagger)$. The lysis time is defined as the time from the initial immersion of a portion of a cell in the lysis buffer zone (Fig. 3e-i) until it is entirely cut (Fig. 3e-ii). The lysis time for individual U87 cells was varied within the range of 10 to $20 \mathrm{~s}$ (Fig. 3d). To investigate the applicability of the device, four more types of adherent cells, including HUVEC (Fig. S12 $\dagger$ ), Caco-2 (Fig. S13 $\dagger$ ), MCF-7 (Fig. S14 $\dagger$ ) and HepG2 cells (Fig. S15†), were successfully cut at desired positions. The results indicated that the Fluid CK was applicable to various types of adherent cells. The lysis times for any two different types of cells showed significant differences. The secretion levels of cell surface proteins and cytoskeleton proteins may contribute to these differences. In further research, mass spectrometric analysis and immunofluorescence analysis may be helpful to understand the differences.

After the entire cutting procedure (Fig. 3e-ii), the cell was cultured in an incubator for wound repair analysis. After $3 \mathrm{~h}$, the cells were co-stained using a Live/Dead kit containing $4.5 \mu \mathrm{mol}$ $\mathrm{L}^{-1}$ propidium iodide (PI) and $2 \mu \mathrm{mol} \mathrm{L}^{-1}$ calcein-AM (Thermo Fisher Scientific, USA) for $15 \mathrm{~min}$. The live cell component is based on a cell-permeable dye for staining of live cells. The dead cell component is a cell-impermeable dye for the staining of dead and dying cells, which are characterized by compromised cell membranes. As shown in Fig. 3f-i, cell spreading was observed. The strong green fluorescence in the merged image (Fig. 3f-ii) indicates the high viability of the cell. Moreover, no red fluorescence was observed in Fig. 3f-ii, which means that the cell had complete cell membranes. The results demonstrate that the cell underwent wound repair.

As the cutting operation was based on destroying the removed part of a cell, it was difficult to avoid damage to the cell. In fact, membrane rupture occurred. The high viability (Fig. 3f-ii) after $3 \mathrm{~h}$ indicated that the operation was safe for the cell. Wound repair of cell plasma is a vital feature distinguishing living from non-living cells. ${ }^{48}$ In some microfluidics approaches, ${ }^{49}$ the probe or key functional part was integrated into the closed microchannel and it was not possible to perform spatial movements. As a result, the cells should move toward the probe or functional part with the fluid, and thus this is not applicable to adherent cells. The Fluid CK technique generated a stable laminar flow with a linear interface in open space that was convenient for treating any target adherent cell. Yet, the Fluid CK cannot be applied to cells in suspension, because the laminar flow is required to keep the cell in the same position. Here, our method provides a new avenue for cell cutting and wound repair studies for adherent cells at single-cell resolution. Furthermore, it is possible to improve the device for opening a cell by generating a curved stream confined by two adjacent flows.

As the stable interface could control the microenvironment for portions of a cell, it was expected to perform well in subcellular molecular infusion. MitoTracker Green FM $(1 \mu \mathrm{M})$ and MitoTracker Deep Red FM $(0.5 \mu \mathrm{M})$ were prepared as the two injection solutions. A single U87 cell was positioned at the interface to carry out subcellular molecular infusion (Fig. 4a). One portion of the cell was stained with MitoTracker Green FM (Fig. 4b), while the other portion was stained with MitoTracker Deep Red FM (Fig. 4c). The mitochondria in the different portions of the cell appeared with different fluorescent colors after $3 \mathrm{~min}$. A clear planar interface was observed between the portion with green fluorescence and the other portion with red fluorescence in the merged fluorescent image the cell (Fig. 4d). In the same manner, ER-Tracker Green $(1 \mu \mathrm{M})$ and ER-Tracker Red $(1 \mu \mathrm{M})$ were used for partial staining of the endoplasmic reticulum in a cell for $5 \mathrm{~min}$ (Fig. $4 \mathrm{e}-\mathrm{h}$ ). All of the results demonstrate that the Fluid CK has excellent performance in subcellular molecular infusion.

As some organelles usually float in the cell contents, we would like to assess the transport of organelles in intracellular environments. The mitochondria were selected as a model organelle. MitoTracker Deep Red FM $(0.5 \mu \mathrm{M})$ and cell culture medium were the two injection solutions, where the cell culture medium was just used for the protection of the portions of the cell immersed in it. The target U87 cell was moved towards and then kept at the interface. After $3 \mathrm{~min}$, the Fluid CK was moved always and the staining was finished (Fig. 5a). It was difficult to record the cell from the beginning, because molecular adsorption on the device caused a big background that had remarkable influences on the cell imaging. For convenience, the recording time for mitochondria transport was defined simply as zero at the time of moving the device away (Fig. 5a). The outlines of the stained portion were set as the boundaries where the fluorescence intensity was three times high than that of the background $(\mathrm{S} / \mathrm{N}=3)$. The fluorescent images over time, with outlines of the stained mitochondria distribution zone, are shown in Fig. 5a-f. The cell was tracked for more than $2 \mathrm{~h}$. After $40 \mathrm{~min}$, the fluorescence had reached the opposite boundary of the cell. Although transport may still continue, no significant changes were observed after $40 \mathrm{~min}$. A color overlap of the outlines is shown in Fig. 5f, and significant transport of the stained mitochondria along line $\mathrm{XX}^{\prime}$ was observed. The profiles of the normalized fluorescence intensity (NFI) at the time of $0 \mathrm{~min}$ and the time of $40 \mathrm{~min}$ appeared with a significant spatial extension along line $\mathrm{XX}^{\prime}$ (Fig. 5g). The temporal changes of the fluorescence intensity at point $\mathrm{A}$ and point $\mathrm{B}$ were recorded (Fig. 5h). The NFI at point A decreased gradually, resulting from the transport of the stained mitochondria towards the upper right and the effect of fluorescence quenching. At the beginning, the NFI of point B increased gradually, and it then decreased under the effects of continuous fluorescence quenching and the decreased transport of stained mitochondria to point B (Fig. 5h). The average transport speed $(V)$ at different time segments was calculated by dividing the moving distance of the transport head (Fig. 5b) by the period of time. The speed decreased gradually because of the continuously decreasing amount of labelled mitochondria at the transport head (Fig. 5i). All the results indicated that our method provides a new approach for subcellular studies and organelle behavior analyses.

Scientists have focused more on single-cell analysis ${ }^{5,10}$ and subcellular studies. ${ }^{36}$ The methods for subcellular operations 

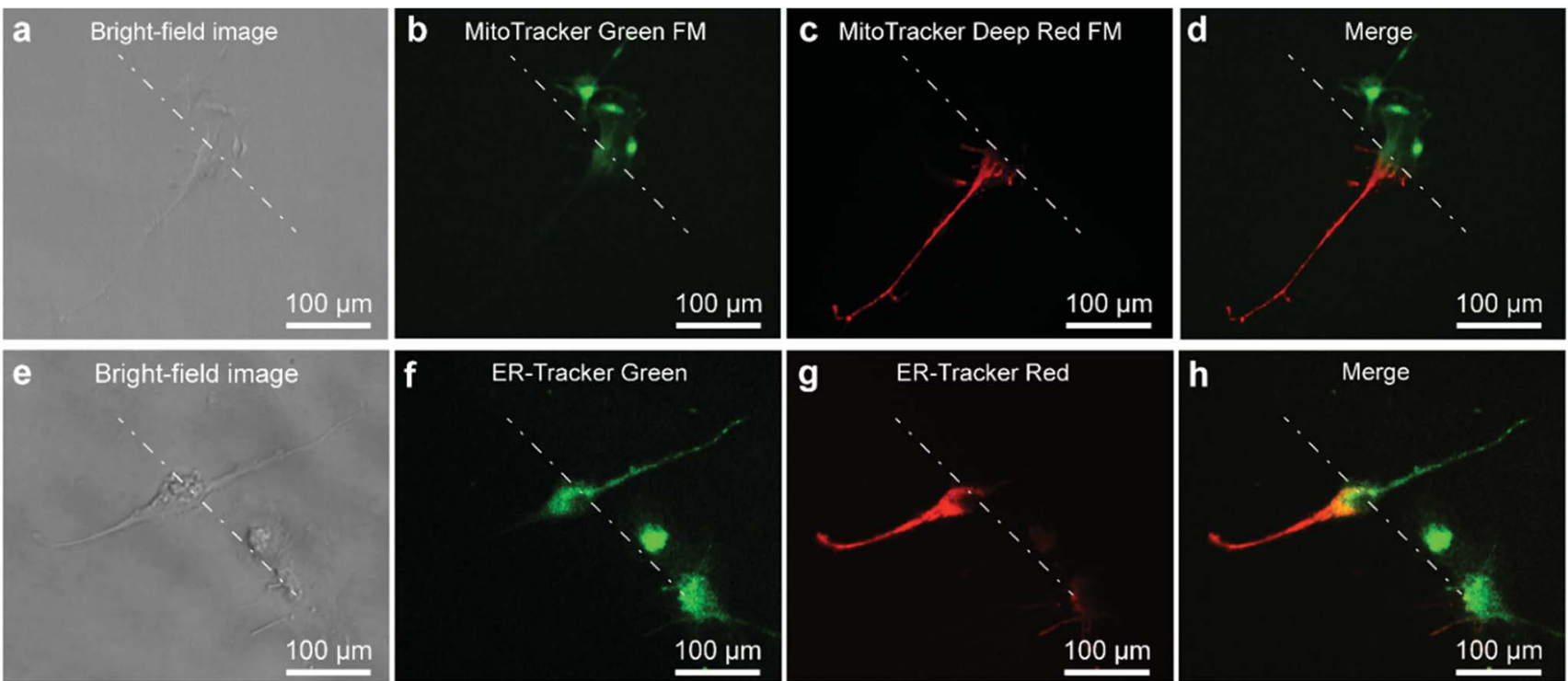

Fig. 4 Precise molecular infusion of a portion of a cell for local staining of partial organelles. (a) A bright-field image of a U87 cell. (b) A fluorescence image of the local staining of the mitochondria in the upper right portion of the cell by MitoTracker Green FM. (c) A fluorescence image of the local staining of the mitochondria in the lower left portion of the cell by MitoTracker Deep Red FM. (d) A merged fluorescence image of the mitochondria in the cell co-stained by the MitoTracker Green FM and MitoTracker Deep Red FM. (e) A bright-field image of a U87 cell. (f) A fluorescence image of the local staining of the ER in the upper right portion of the cell by ER-Tracker Green. (g) A fluorescence image of the local staining of the ER in the lower left portion of the cell by ER-Tracker Red. (h) A merged fluorescence image of the ER in the cell co-stained by the ER-Tracker Green and ER-Tracker Red.
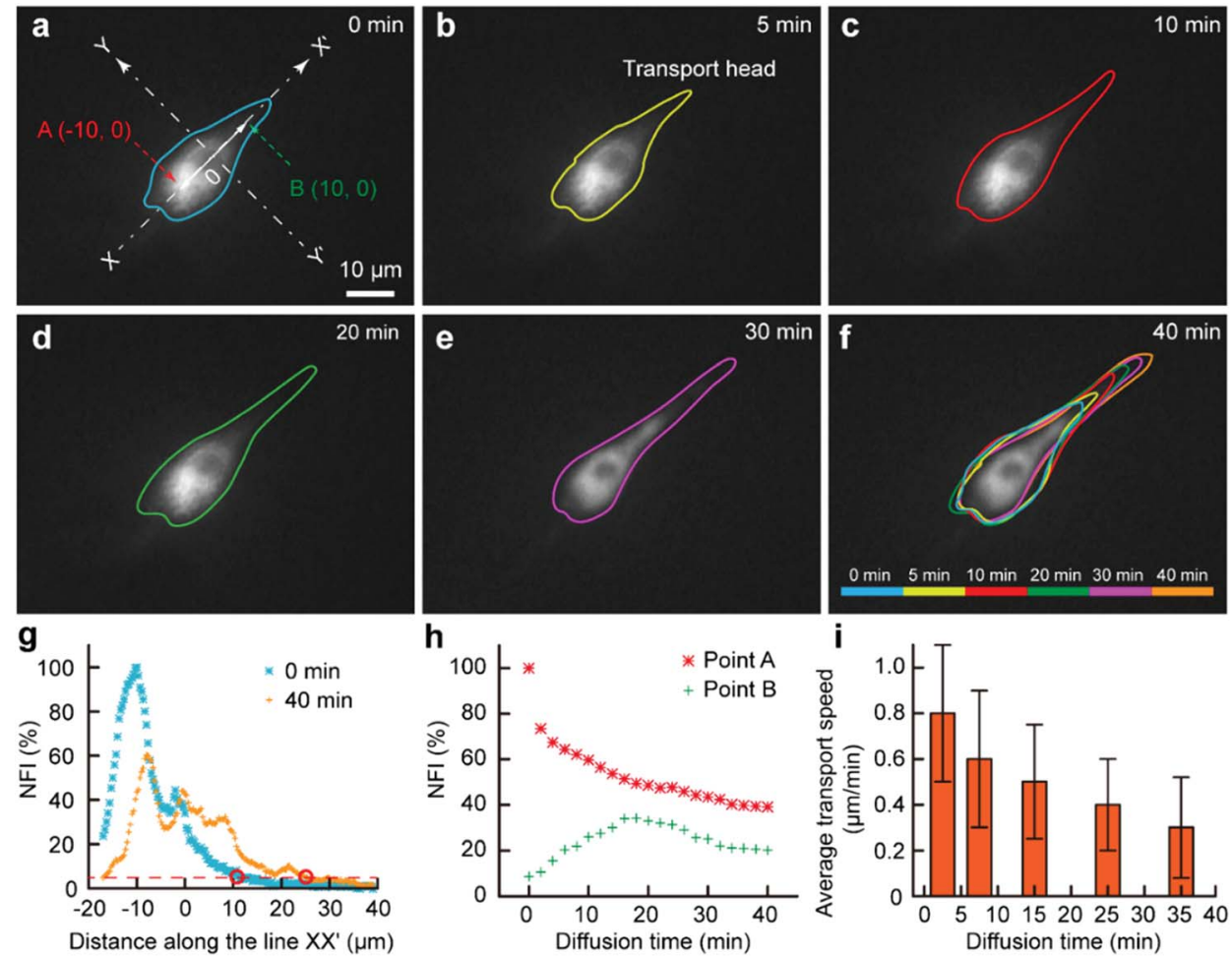

Fig. 5 Subcellular molecular infusion for monitoring organelle transport in a single cell. Fluorescent images for the spatial transport of the labelled mitochondria as time went by (a) $0 \mathrm{~min}$, (b) $5 \mathrm{~min}$, (c) $10 \mathrm{~min}$, (d) $20 \mathrm{~min}$, (e) $30 \mathrm{~min}$ and (f) $40 \mathrm{~min}$. An overlap of the fluorescent boundaries of the cell at different times is shown in (f). (g) Fluorescence intensity profile along the line $X X^{\prime}$ perpendicular to the interface $Y Y^{\prime}$ at 0 min and $40 \mathrm{~min}$. (h) The variation of the fluorescence intensity at points $A(-10,0)$ and $B(10,0)$ on the line XX' as time went by. (i) Measured transport speed at different time segments. 
will be applicable to understanding how single cells heal membrane ruptures and restore lost structures. The physical and molecular mechanisms for cell healing remains poorly understood..$^{13}$ Our method, capable of damaging part of a cell, might be a potential approach for studying membrane rebuilding. Moreover, signal transmission is an essential function in a cell. ${ }^{50}$ The capability of subcellular molecular infusion will be helpful for investigating signal transmission in a living cell.

\section{Conclusions}

In this work, we have established a novel method for chemical operations on single cells, including precise cell cutting operations and subcellular molecular infusion. A fluid cell knife was developed to carry out those tasks. The device was proved to be a universal approach for precise cell cutting operations for various types of adherent cells. Significantly, wound repair was observed for the cut cell. The Fluid CK was capable of subcellular infusion of molecules into portions of a cell. Moreover, the transport behavior of the organelle, mitochondria, was explored, and the transport speed was obtained. Our results indicate that partial treatment using laminar flows in open space generated by the Fluid CK is an effective way to deliver small molecules to selected domains inside a single mammalian cell. This technique opens up avenues for the control of subcellular microenvironments, precise cellular cutting, wound repair analysis and subcellular molecular infusion.

\section{Conflicts of interest}

There are no conflicts to declare.

\section{Acknowledgements}

We acknowledge the National Natural Science Foundation of China (No. 21435002, 21727814 and 21621003), the Beijing Natural Science Foundation (2184106) and the China Postdoctoral Science Foundation (2018T110085, 2017M620733).

\section{Notes and references}

1 C. Lombard-Banek, S. A. Moody and P. Nemes, Angew. Chem., Int. Ed., 2016, 55, 2454-2458.

2 R. M. Onjiko, S. A. Moody and P. Nemes, Proc. Natl. Acad. Sci. U. S. A., 2015, 112, 6545.

3 A. M. Klein, L. Mazutis, I. Akartuna, N. Tallapragada, A. Veres, V. Li, L. Peshkin, D. A. Weitz and M. W. Kirschner, Cell, 2015, 161, 1187-1201.

4 S. Mao, W. Zhang, Q. Huang, M. Khan, H. Li, K. Uchiyama and J. M. Lin, Angew. Chem., Int. Ed., 2018, 57, 236-240.

5 A. Giladi and I. Amit, Nature, 2017, 547, 27.

6 H. Yukawa and Y. Baba, Anal. Chem., 2017, 89, 2671-2681.

7 J. Lu, X. Zhong, H. Liu, L. Hao, C. T.-L. Huang, M. A. Sherafat, J. Jones, M. Ayala, L. Li and S.-C. Zhang, Nat. Biotechnol., 2016, 34, 89-94.
8 R. N. Zare and S. Kim, Annu. Rev. Biomed. Eng., 2010, 12, 187201.

9 L. Hao, J. Johnson, C. B. Lietz, A. Buchberger, D. Frost, W. J. Kao and L. Li, Anal. Chem., 2017, 89, 1138-1146.

10 E. Callaway, Nature, 2017, 547, 20.

11 X. T. Li, S. L. Zhao, H. K. Hu and Y. M. Liu, J. Chromatogr. A, 2016, 1451, 156-163.

12 Y. Gai, C. M. Leong, W. Cai and S. K. Y. Tang, Proc. Natl. Acad. Sci. U. S. A., 2016, 113, 12082-12087.

13 S. K. Y. Tang and W. F. Marshall, Science, 2017, 356, 1022.

14 C. H. Lu, C. L. Zhu, J. Li, J. J. Liu, X. Chen and H. H. Yang, Chem. Commun., 2010, 46, 3116-3118.

15 X. Fu, W. J. Shang, S. S. Wang, Y. P. Liu, J. Y. Qu, X. Chen, P. G. Wang and J. Q. Fang, Chem. Commun., 2017, 53, 3555-3558.

16 M. P. Macdonald, G. C. Spalding and K. Dholakia, Nature, 2003, 426, 421.

17 V. V. Kotlyar, A. A. Kovalev and A. P. Porfirev, J. Appl. Phys., 2016, 120, 023101.

18 S. Khakshour, M. P. Labrecque, H. Esmaeilsabzali, F. J. S. Lee, M. E. Cox, E. J. Park and T. V. Beischlag, Sci. Rep., 2017, 7, 7833.

19 M. E. Gallina, T. J. Kim, M. Shelor, J. Vasquez, A. Mongersun, M. Kim, S. K. Y. Tang, P. Abbyad and G. Pratx, Anal. Chem., 2017, 89, 6472-6481.

20 M. Tabuchi, M. Ueda, N. Kaji, Y. Yamasaki, Y. Nagasaki, K. Yoshikawa, K. Kataoka and Y. Baba, Nat. Biotechnol., 2004, 22, 337.

21 A. Ainla, E. T. Jansson, N. Stepanyants, O. Orwar and A. Jesorka, Anal.Chem., 2010, 82, 4529-4536.

22 D. Juncker, H. Schmid and E. Delamarche, Nat. Mater., 2005, 4, 622-628.

23 R.-C. Qian, Y. Cao, L.-J. Zhao, Z. Gu and Y.-T. Long, Angew. Chem., Int. Ed., 2017, 56, 4802-4805.

24 H. Tian, Y. Sun, C. Liu, X. Duan, W. Tang and Z. Li, Anal. Chem., 2016, 88, 11384-11389.

25 Q. Huang, S. Mao, M. Khan, L. Zhou and J. M. Lin, Chem. Commun., 2018, 54, 2598.

26 Y. Fu, H. Chen, L. Liu and Y. Huang, Anal. Chem., 2016, 88, 10795-10799.

27 M. Kaiser, F. Jug, T. Julou, S. Deshpande, T. Pfohl, O. K. Silander, G. Myers and E. van Nimwegen, Nat. Commun., 2018, 9, 212.

28 T. Nagano, Y. Lubling, C. Vaarnai, C. Dudley, W. Leung, Y. Baran, N. M. Cohen, S. Wingett, P. Fraser and A. Tanay, Nature, 2017, 547, 61-68.

29 T. Fujii, S. Matsuda, M. L. Tejedor, T. Esaki, I. Sakane, H. Mizuno, N. Tsuyama and T. Masujima, Nat. Protoc., 2015, 10, 1445-1456.

30 H. Mizuno, N. Tsuyama, T. Harada and T. Masujima, J. Mass Spectrom., 2008, 43, 1692-1700.

31 X. Y. Gong, Y. Y. Zhao, S. Q. Cai, S. J. Fu, C. D. Yang, S. C. Zhang and X. R. Zhang, Anal. Chem., 2014, 86, 38093816.

32 O. Guillaume-Gentil, T. Rey, P. Kiefer, A. J. Ibáñez, R. Steinhoff, R. Brönnimann, L. Dorwling-Carter, 
T. Zambelli, R. Zenobi and J. A. Vorholt, Anal. Chem., 2017, 89, 5017-5023.

33 O. Guillaumegentil, R. V. Grindberg, R. Kooger,

L. Dorwlingcarter, V. Martinez, D. Ossola, M. Pilhofer, T. Zambelli and J. A. Vorholt, Cell, 2016, 166, 506-516.

34 A. Meister, M. Gabi, P. Behr, P. Studer, J. Vörös, P. Niedermann, J. Bitterli, J. Polesel-Maris, M. Liley, H. Heinzelmann and T. Zambelli, Nano Lett., 2009, 9, 2501-2507.

35 R. A. Moffitt, R. Marayati, E. L. Flate, K. E. Volmar, S. G. H. Loeza, K. A. Hoadley, N. U. Rashid, L. A. Williams, S. C. Eaton, A. H. Chung, J. K. Smyla, J. M. Anderson, H. J. Kim, D. J. Bentrem, M. S. Talamonti, C. A. IacobuzioDonahue, M. A. Hollingsworth and J. J. Yeh, Nat. Genet., 2015, 47, 1168.

36 S. Takayama, E. Ostuni, P. LeDuc, K. Naruse, D. E. Ingber and G. M. Whitesides, Nature, 2001, 411, 1016.

37 J. Atencia and D. J. Beebe, Nature, 2002, 437, 648-655.

38 M. A. Qasaimeh, T. Gervais and D. Juncker, Nat. Commun., 2011, 2, 464.

39 G. V. Kaigala, R. D. Lovchik and E. Delamarche, Angew. Chem., Int. Ed., 2012, 51, 11224-11240.

40 Y. Zhang, S. Mao, Y. Suzuki, Y. Tanaka, M. Kawaguchi, W. Zhang, H. Zeng, H. Nakajima, M. Yang and K. Uchiyama, Chem. Commun., 2018, 54, 719-722.
41 S. Mao, C. Sato, Y. Suzuki, J. Yang, H. Zeng, H. Nakajima, M. Yang, J.-M. Lin and K. Uchiyama, ChemPhysChem, 2016, 17, 3155-3159.

42 S. Mao, Y. Zhang, H. Li, H. Zeng, J. M. Lin and K. Uchiyama, J. Mater. Chem. C, 2017, 5, 11666-11671.

43 A. Queval, N. R. Ghattamaneni, C. M. Perrault, R. Gill, M. Mirzaei, R. A. McKinney and D. Juncker, Lab Chip, 2010, 10, 326-334.

44 J. Autebert, A. Kashyap, R. D. Lovchik, E. Delamarche and G. V. Kaigala, Langmuir, 2014, 30, 3640-3645.

45 O. Feinerman and E. Moses, J. Neurosci. Methods, 2003, 127, 75-84.

46 M. Abadier, A. B. Pramod, S. McArdle, A. Marki, Z. C. Fan, E. Gutierrez, A. Groisman and K. Ley, Cell Rep., 2017, 21, 3885-3899.

47 Z. He, W. Zhang, S. Mao, N. Li, H. Li and J.-M. Lin, Anal. Chem., 2018, 90, 5540-5545.

48 D. R. Griffin, W. M. Weaver, P. O. Scumpia, D. Di Carlo and T. Segura, Nat. Mater., 2015, 14, 737-744.

49 L. R. Blauch, Y. Gai, J. W. Khor, P. Sood, W. F. Marshall and S. K. Y. Tang, Proc. Natl. Acad. Sci. U. S. A., 2017, 114, 7283.

50 Y. E. Korchev, Y. A. Negulyaev, C. R. W. Edwards, I. Vodyanoy and M. J. Lab, Nat. Cell Biol., 2000, 2, 616. 